\title{
MODELLING THE STABILITY OF ASPHALT CONCRETE WITH FUZZY LOGIC AND STATISTICAL METHODS FOR VARIOUS FREEZING AND THAWING CYCLES
}

\author{
Ercan Özgan \\ Technical Education Faculty Department of Structural Education \\ Düzce University, 81100 \\ Konuralp, Düzce, Turkey \\ ercanozgan@gmail.com
}

\begin{abstract}
The stability of asphalt concrete under the effects of freezing and thawing was studied experimentally, and the experimental test results were modelled using fuzzy logic and statistical methods. The stability was investigated experimentally using the Marshall and ultrasound methods. Asphalt core samples $10 \mathrm{~cm}$ in diameter were alternately frozen $\left(-20^{\circ} \mathrm{C}\right.$ for $\left.16 \mathrm{hr}\right)$ and thawed $\left(16^{\circ} \mathrm{C}\right.$ for $\left.8 \mathrm{hr}\right)$ for $5,10,15,20,25$, and 30 cycles to simulate daily winter conditions. The stability of asphalt concrete at the laboratory environment temperature of $17^{\circ} \mathrm{C}$ was used as a reference. The results showed that the stability of asphalt core samples exposed to freezing and thawing increased, and this increase varied between $22.7 \%$ and $19.2 \%$ for 5 - and 30 -day cycles, respectively. By using Fuzzy Logic and statistical methods, prediction models were constituted based on freezing-thawing cycle, bitumen ratio, saturated unit volume weight, volume of voids, air dry unit volume weight to predict the Stability of asphalt concrete which could not be determined with experimental. The experimental results, the fuzzy logic model, and the statistical results showed good correlations. For the stability of asphalt core samples, the correlation coefficient was $\mathrm{R}^{2}=0.88$ for the fuzzy logic model and $\mathrm{R}^{2}=1.0$ for the statistical method. Based on the results of this study, it is clear that both the fuzzy logic and statistical methods can be used to model the stability of asphalt concrete under various freezing and thawing conditions.
\end{abstract}

Key Words- Marshall Stability; Freezing-Thawing; Fuzzy Logic; Statistical Modelling

\section{INTRODUCTION}

Paved roads represent a huge investment. As most surfaced roads are covered with flexible pavement, one of the most important problems is stripping or the loss of adhesion between the asphalt coating and the aggregate in the bituminous mixture caused by the existence of moisture. Stripping can cause different types of distress, such as creep, ravelling, rutting, shoving, cracking and low stability. This hot mix asphalt (HMA) environmental damage is a material compatibility problem. If the materials are compatible, they will form strong and long-term bonds so that the HMA will resist stripping. However, if the mix has poor bonding, its resistance to stripping will be reduced. In this case, the bonds should be enhanced or the material combinations should be changed to achieve satisfactory performance. Stripping is one of the most difficult forms of distress to identify because it can take numerous forms and is influenced by many variables. Some of these variables are related to the HMA materials used, such as 
the aggregate, asphalt cement and anti-stripping agents. Other variables are related to the weather conditioning, compaction, air voids, testing methods, handling and storage conditions of additives.

Moreover, stripping is a rate process based on the viscosity-temperature dependency of bituminous binders. In addition, stripping is a function of the surface tension between the aggregate and bitumen [1]. Damage to highways occurs mostly on the top layer of the roadway in the binder and erosion layers and not in the foundation or lower layers. Damage to the binder and erosion layers generally consists of surface cracks, deformations, wheel ruts and pot-holes. Temperature effects are the main cause of damage to highway pavement and affect performance. It is very important to determine the effects of increasing or decreasing temperatures to understand asphalt concrete stability. Increasing temperature decreases the stability of asphalt concrete and also decreases the viscosity of the bitumen. The stability of asphalt concrete determines the performance of highway pavement. Low stability of asphalt concrete may lead to various types of distress in the asphalt pavement [2]. The stability of asphalt concrete pavements depends on the stiffness of the mix, the bitumen content, the softening point and viscosity of the bitumen, the aggregate grading, construction practices, traffic and climate conditions [3]. The influence of bitumen rheology on the low-temperature behaviour of asphalt mixtures has been investigated in the laboratory environment [4]. The triaxial and stress relaxation tests conducted by Monismith and Secor are used as benchmarks for determining the effectiveness of the model for predicting the mechanical response characteristics of asphalt concrete over a wide range of temperatures and confining pressures [5]. The effects of varying temperatures and exposure times on the stability of asphalt concrete using destructive and non-destructive methods were examined, and the relationship between destructive and non-destructive methods was determined to be $\mathrm{R}^{2}=-0.53$ [6]. The ambient temperature was found to significantly affect the stability of the asphalt concrete. Higher temperature increases both the viscosity and the ductility of asphalt cements. As a result of this viscositytemperature dependency of asphalt materials, it has been suggested that the relevant performance of HMA mixtures has a strong relationship with the mixing temperatures in the central plant and the compaction temperatures in the field [7-16]. This has been widely used to determine the mixing and compaction temperatures for both laboratory experiments and field construction [17]. It has been determined that both exposure time and environmental temperature affect the ductility of asphalt cement [18]. Increasing viscosity and ductility decrease the stability of asphalt concrete, resulting in problems that are considered major contributors to early or premature distress of asphalt pavement, including segregation, numerous air voids, inadequately mixed content and a compaction temperature that is too low $[8,19-22]$. On the other hand, understanding the effects of freezing and thawing cycles on the stability of asphalt concrete is as important as knowing the impact of increasing the temperature.

In this study, the effects of freezing/thawing cycles on the stability of asphalt concrete were investigated. The stability and ultrasound velocity of asphalt core samples that had been exposed to different freezing/thawing cycles were measured experimentally. For simulation and modelling of asphalt concrete stability in different freezing/thawing cycles, the experimental results were analysed using statistical and fuzzy logic methods. By using fuzzy logic and statistical methods, prediction models 
were constituted based on freezing-thawing cycle, bitumen ratio, saturated unit volume weight, volume of voids, air dry unit volume weight to predict the Marshall Stability of asphalt concrete which could not be determined with experiment.

\section{EXPERIMENTAL DETAILS}

\subsection{Asphalt core samples}

A total of 35 asphalt core samples were used in this study. The samples were extracted from a section of the D100-11 state highway in the city of Düzce, Turkey. The asphalt cement used in the core samples was from the Aliağa refinery in Izmir. Of these, 5 served as a reference and the remaining 30 were separated into 6 groups of 5 samples each for freeze/thaw cycle times of 5, 10, 15, 20, 25, and 30 days. Sample groups for the 6 different cycle times are shown in Fig. 1.

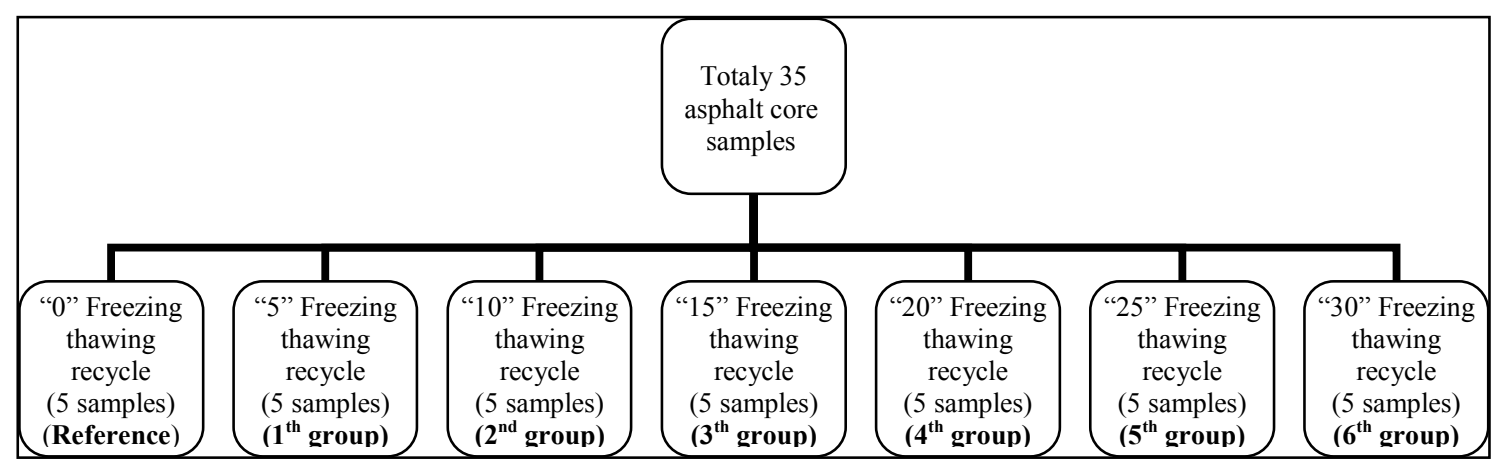

Figure1. Sample groups for the 6 different cycle times.

\subsection{Freezing/thawing tests}

To determine the stability of asphalt core samples subjected to varying freezing/thawing cycles, 5 of the 35 samples were selected at random and maintained at $17^{\circ} \mathrm{C}$ in the laboratory environment. The stability and ultrasound velocities of these 5 specimens were used as reference properties for the other 30 samples that were subjected to cyclic freezing $\left(-20^{\circ} \mathrm{C}\right.$ for $\left.16 \mathrm{hr}\right)$ and thawing $\left(16^{\circ} \mathrm{C}\right.$ for $8 \mathrm{hr}$ in water) to simulate the daily winter conditions.

\subsection{Extraction tests for asphalt core samples}

Extraction tests were performed according to ASTM D2172 using a 3600-rpm centrifuge extractor to determine the quantity of bitumen for all core samples [23]. In these tests, trichloroethylene was used to decompose the bitumen from aggregates in the core samples. The measured quantity of bitumen in the asphalt core samples was in the range $7.31-9.71 \%$.

\subsection{Aggregate properties}

One of the most important properties of aggregates used in asphalt pavements is their resistance to freezing and thawing. The effects of freezing and thawing occur at different levels in the various pavement layers. The aggregates used in wearing courses must be more durable than those used in binder courses, and must not disintegrate when frozen. The physical and mechanical properties of aggregates may be adversely affected 
by freezing and thawing. However, such adverse effects must be minimised for aggregates used in pavement construction. The aggregates used in the wearing course must be better than those used in other courses. Although the aggregates used in the base, sub-base and binder courses do not have to be of high quality, the binder aggregates must still meet certain physical and mechanical specifications. The aggregates used in the asphalt core samples have been taken from the quarries in the Hasanlar Dam region near Düzce, Turkey. The physical properties of the aggregates used are summarised in Table1.

Table 1 . The physical properties of the aggregates used in asphalt core samples

Sieve analysis was performed on the aggregates and the results of sieve analysis

\begin{tabular}{lccc}
\hline \multirow{2}{*}{ Aggregate } & $\begin{array}{c}\text { Dry bulk } \\
\text { specific gravity }\end{array}$ & $\begin{array}{c}\text { Apparent specific } \\
\text { gravity }\end{array}$ & $\begin{array}{c}\text { Absorption } \\
(\%)\end{array}$ \\
\cline { 2 - 4 } & Limestone & Limestone & Limestone \\
\hline Mineral filler & 2.549 & 2.628 & 5.3 \\
\hline Fine aggregate & 2.481 & 2.586 & 4.5 \\
\hline Coarse aggregate & 2.427 & 2.575 & 3.2 \\
\hline
\end{tabular}

according to the sieve number and passing ratio are given in Table 2 .

Table 2. The results of sieve analysis according to the sieve number and passing ratio

\begin{tabular}{lcccccccc}
\hline Sieve no & 230 & 120 & 100 & 80 & 60 & 40 & 35 & 18 \\
\hline Passing ratio (\%) & $\mathbf{3 , 3 3}$ & $\mathbf{5 , 2 5}$ & $\mathbf{5 , 8 4}$ & $\mathbf{6 , 5 8}$ & $\mathbf{8 , 0 8}$ & $\mathbf{1 1 , 3 3}$ & $\mathbf{1 2 , 6 3}$ & $\mathbf{1 9 , 7 9}$ \\
\hline & & & & & & & & \\
\hline Sieve no (continuous) & 10 & 4 & $5 / 6 "$ & $3 / 8 ”$ & $1 / 2 ”$ & $5 / 8 ”$ & $3 / 4 "$ & $1 "$ \\
\hline Passing ratio (\%) & $\mathbf{3 2 , 6 0}$ & $\mathbf{5 9 , 9 7}$ & $\mathbf{7 2 , 1 9}$ & $\mathbf{7 7 , 7 9}$ & $\mathbf{8 7 , 0 3}$ & $\mathbf{9 4 , 1 4}$ & $\mathbf{9 8 , 7 5}$ & $\mathbf{1 0 0}$ \\
\hline
\end{tabular}

\section{MODELLING OF EXPERIMENTAL TEST RESULTS}

The experimental test results showed that the stability of the asphalt core samples exposed to different freezing and thawing cycles increased, and this increase varied from $22.7 \%$ for the 5 -day cycle to $19.2 \%$ for the 30 -day cycle. The relationships between experimental test results, statistical analysis and fuzzy logic model results showed good correlations; the correlation coefficients for the stability of asphalt core samples were $\mathrm{R}^{2}=0.88$ for the fuzzy logic model and $\mathrm{R}^{2}=1.0$ for the statistical method.

\section{STATISTICAL ANALYSIS}

Statistical analyses were performed for all of the asphalt core sample properties: volume of voids, unit volume weight for saturated surface, unit volume weight for dry air, environmental temperature, exposure time, bitumen percentage, flow (caving in) and stability. The relationships between stability, ultrasound velocity and the other characteristic properties of the asphalt core samples were determined using the SPSS statistical software. Descriptive statistics, correlation coefficients, multi-linear regression analysis and analysis of variance were also performed, and the results of statistical analyses are given in Table3. 
Table 3. The results of statistical analyses

\begin{tabular}{lccccccc}
\hline & Range & Min. & Max. & \multicolumn{2}{c}{ Mean } & $\begin{array}{c}\text { Std. } \\
\text { Deviation }\end{array}$ & Variance \\
\hline & Statistic & Statistic & Statistic & Statistic & Std. Err. & Statistic & Statistic \\
\hline $\begin{array}{l}\text { Freezing-thawing } \\
\text { cycle }\end{array}$ & 30 & 0 & 30 & 15,00 & 4,08 & 10,80 & 116,667 \\
\hline Marshall Stability & 1011 & 4367 & 5378 & 4887,14 & 140,95 & 372,92 & 139069,143 \\
\hline $\begin{array}{l}\text { Flow (caving in) } \\
1^{\text {st Ultrasound }}\end{array}$ & 4,62 & 2,05 & 6,67 & 5,1271 &, 5514 & 1,4587 & 2,128 \\
$\begin{array}{l}\text { velocity } \\
2^{\text {st } U l t r a s o u n d ~}\end{array}$ & 2,28 & 18,40 & 20,68 & 19,4571 &, 2925 &, 7738 &, 599 \\
\hline $\begin{array}{l}\text { velocity } \\
\text { Volume of voids }\end{array}$ & 6,54 & 18,72 & 21,30 & 19,9829 &, 3573 &, 9454 &, 894 \\
\hline $\begin{array}{l}\text { Saturated unit } \\
\text { volume weight }\end{array}$ &, 09 & 2,34 & 2,43 & 2,3829 & 0,0128 & 0,0340 & 0,0011 \\
\hline $\begin{array}{l}\text { Air dry unit } \\
\text { volume weight }\end{array}$ &, 11 & 2,31 & 2,42 & 2,3700 & 0,0149 & 0,0395 & 0,0015 \\
\hline Bitumen ratio & 2,57 & 7,14 & 9,71 & 7,9971 &, 3277 &, 8669 &, 751 \\
\hline
\end{tabular}

\subsection{Relationship between stability, ultrasound velocity and other characteristic properties for asphalt core samples}

Correlation analysis was performed to determine the significance levels and the relationships between all variables and the results are shown in Table 4.

Table 4. The relationships between all variables at 0.05 levels

\begin{tabular}{|c|c|c|c|c|c|c|c|c|c|}
\hline & 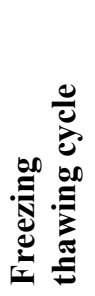 & 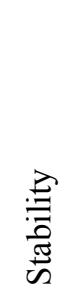 & $\frac{3}{2}$ & 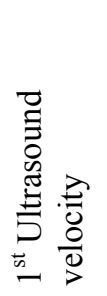 & 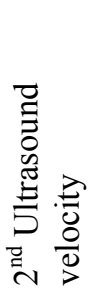 & 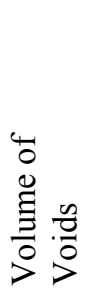 & 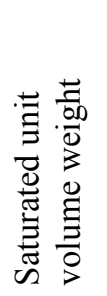 & 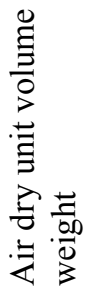 & $\begin{array}{l}e^{20} \\
\stackrel{\Xi}{0} \\
\stackrel{\Xi}{\Xi}\end{array}$ \\
\hline Freezing thawing cycle & 1,0 &, 18 & 45 & ,698 &,- 53 &,- 28 & ,32 & 37 &,- 21 \\
\hline Marshall Stability & ,18 & 1,00 &,- 35 &,- 29 & ,18 &,- 93 &,- 30 &,- 28 &,- 59 \\
\hline Flow & ,45 &,- 35 & 1,0 & 45 &,- 01 & ,18 & ,09 & ,171 &, 15 \\
\hline$* 1^{\text {th }}$ Ultrasound velocity & ,70 &,- 29 & 45 & 1,0 &,- 73 & 17 &, 80 &, 77 &,- 08 \\
\hline $\begin{array}{l}* * 2^{\text {nd }} \\
\text { Ultrasound velocity }\end{array}$ &,- 53 &, 18 &,- 01 &,- 73 & 1,00 & ,02 &,- 90 &,- 92 &, 32 \\
\hline Volume of voids &,- 28 &,- 93 &, 18 &, 17 & ,02 & 1,0 &, 11 & ,03 & ,81 \\
\hline Saturated unit volume weight &, 32 &,- 30 & ,09 & ,80 &,- 90 & 11 & 1,00 & ,98 &,- 29 \\
\hline Air dry unit volume weight & ,37 &,- 28 & 17 & ,77 &,- 92 &, 03 & ,98 & 1,00 &,- 39 \\
\hline Bitumen (\%) &,- 21 &,- 59 &, 15 &,- 08 & ,32 & ,81 &,- 29 &,- 39 & 1,00 \\
\hline
\end{tabular}

The results regarding the relationship between stability and the other variables were as follows: freezing/thawing cycle, 0.18; flow, 0.35; first ultrasound velocity before freezing/thawing, 0.29; second ultrasound velocity after freezing/thawing, 0.18 ; volume of voids, 0.93; saturated unit volume weight, 0.3; air dry unit volume weight, 0.28 ; and quantity of bitumen, 0.59 . 


\subsection{Prediction of stability based on physical properties, ultrasound velocity and daily freezing/thawing cycle}

Multi-linear regression analysis (MLR) and analysis of variance (ANOVA) were performed to determine the relationships between volume of voids, saturated unit volume weight, dry air unit volume weight, ultrasound velocity, freezing/thawing cycles and stability. A model equation was developed using MLR analysis to predict the Marshall stability (S) based on first ultrasound velocity (x1), volume of voids (x2), saturated unit volume weight (x3), dry air unit volume weight $(\mathrm{x} 4)$, bitumen ratio $(\mathrm{x} 5)$ and freezing/thawing cycles $(\mathrm{x} 6)$. The correlation coefficient $(\mathrm{R})$ was determined to be 1.0. The results of MLR are presented in Tables 5(a), (b) and (c).

Table5. The results of MLR

a. Model Summary

\begin{tabular}{cccccccccc}
\hline Model & $\mathrm{R}$ & R Square & $\begin{array}{c}\text { Adjusted R } \\
\text { Square }\end{array}$ & $\begin{array}{c}\text { Std. Error of the } \\
\text { Estimate }\end{array}$ & $\begin{array}{c}\text { R Square } \\
\text { Change }\end{array}$ & F Change df1 df2 & $\begin{array}{c}\text { Sig. F } \\
\text { Change }\end{array}$ \\
\hline 1,000 & 1,000 & 1,000 &, & 1,000 &, & 6 & 0 & , \\
\hline
\end{tabular}

a Predictors: (Constant), Freezing-thawing cycle, Bitumen ratio, Saturated unit volume weight, volume of voids, $1^{\text {st }}$ Ultrasound velocity and air dry unit volume weight.

b.ANOVA

\begin{tabular}{ccccccc}
\hline Model & & Sum of Squares & df & Mean Square & F & Sig. \\
\hline \multirow{3}{*}{1} & Regression & 834414,857 & 6 & 139069,143 & & , \\
\cline { 2 - 7 } & Residual &, 000 & 0 & & & \\
\cline { 2 - 7 } & Total & 834414,857 & 6 & & & \\
\hline
\end{tabular}

a Predictors: (Constant), Freezing-thawing cycle, Bitumen ratio, Saturated unit volume weight, volume of voids, $1^{\text {st }}$ Ultrasound velocity and air dry unit volume weight. b Dependent Variable: Stability c.Coefficients

\begin{tabular}{|c|c|c|c|c|c|c|}
\hline & \multirow[t]{2}{*}{ Model } & \multirow{2}{*}{$\begin{array}{c}\begin{array}{c}\text { Unstandardized } \\
\text { Coefficients }\end{array} \\
\text { B }\end{array}$} & & $\begin{array}{c}\text { Standardized } \\
\text { Coefficients }\end{array}$ & \multirow[t]{2}{*}{$\mathrm{t}$} & \multirow[t]{2}{*}{ Sig. } \\
\hline & & & Std. Error & Beta & & \\
\hline \multirow{7}{*}{1} & (Constant) & 2355,956 &, 000 & & , & , \\
\hline & $1^{\text {st }}$ Ultrasound velocity & $-99,387$ &, 000 &,- 206 & , & 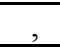 \\
\hline & Volume of voids & $-141,012$ &, 000 & $-1,131$ & , & 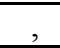 \\
\hline & Saturated unit volume weight & 16598,115 & ,000 & 1,514 & , & , \\
\hline & Air dry unit volume weight & $-14562,623$ &, 000 & $-1,546$ & , & 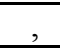 \\
\hline & Bitumen ratio & 78,592 &, 000 &, 183 & , & , \\
\hline & Freezing-thawing cycle & 4,617 &, 000 &, 134 & , & , \\
\hline
\end{tabular}

a Dependent Variable: Stability

$S=2355.956+99.387 x_{1}+141.012 x_{2}+16598.115 x_{3}+14562.623 x_{4}+78.592 x_{5}+4.617 x_{6}$

Where; $\mathrm{S}$ : stability $(\mathrm{kg}), \mathrm{x}_{1}$ : first ultrasound velocity before freezing/thawing ( $\left.\mu \mathrm{s}\right)$, $\mathrm{x}_{2}$ : volume of voids $\left(\mathrm{cm}^{3}\right), \mathrm{x}_{3}$ : saturated unit volume weight $\left(\mathrm{g} / \mathrm{cm}^{3}\right)$, $\mathrm{x}_{4}$ : dry air unit volume weight $\left(\mathrm{g} / \mathrm{cm}^{3}\right), \mathrm{x}_{5}$ : bitumen ratio $(\%)$ and $\mathrm{x}_{6}$ : freezing-thawing cycle (days). 


\section{MODELLING OF EXPERIMENTAL TEST RESULTS WITH THE FUZZY LOGIC METHOD}

Together with statistical analysis, fuzzy logic was applied to predict the stability of asphalt core samples under varying freezing/thawing conditions. The fuzzy logic method includes the fuzzy inference system (FIS), membership functions (MF), rule editors, a rule viewer and a surface viewer.

\subsection{Fuzzy inference systems (FIS)}

The process of fuzzy inference involves all components of membership functions, fuzzy logic operators and if-then rules. The two types of FIS are the Mamdani and Sugeno types [24-26]. A Mamdani FIS was used in this study to model the stability of asphalt concrete. The first ultrasound velocities before freezing/thawing $\left(\mathrm{x}_{1}\right)$, volume og voids $\left(\mathrm{x}_{2}\right)$, saturated unit volume weight $\left(\mathrm{x}_{3}\right)$, air dry unit volume weight $\left(\mathrm{x}_{4}\right)$, bitumen ratio $\left(\mathrm{x}_{5}\right)$ and number of freezing-thawing cycles $\left(\mathrm{x}_{6}\right)$ were used as inputs, and the stability of asphalt concrete and the second ultrasound velocity after freezing-thawing cycles were used as outputs. The FIS is shown schematically in Fig2.

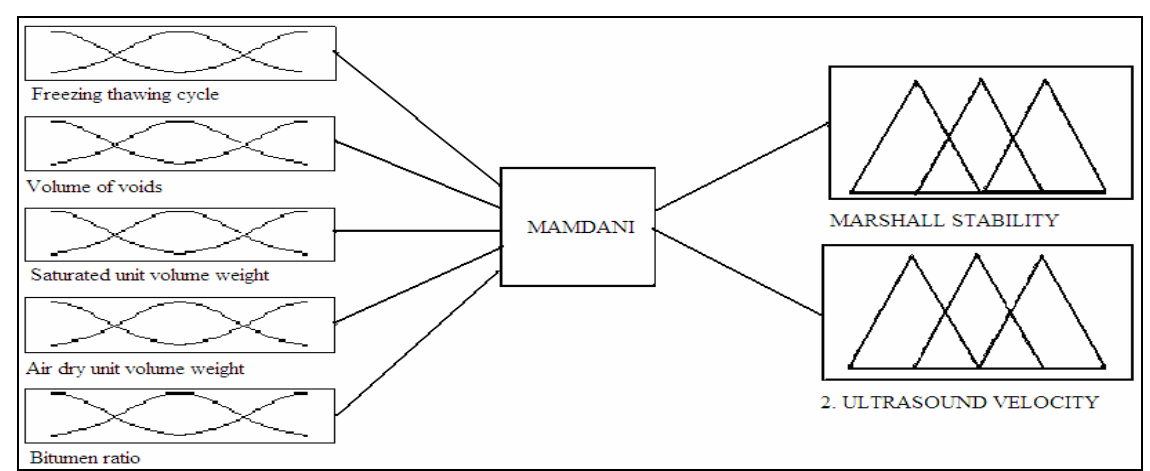

Figure2. Fuzzy inference system for stability and ultrasound velocity

\subsection{Membership Functions (MF)}

The degree of membership " $\mu$ " is shown for stability in Fig.3.

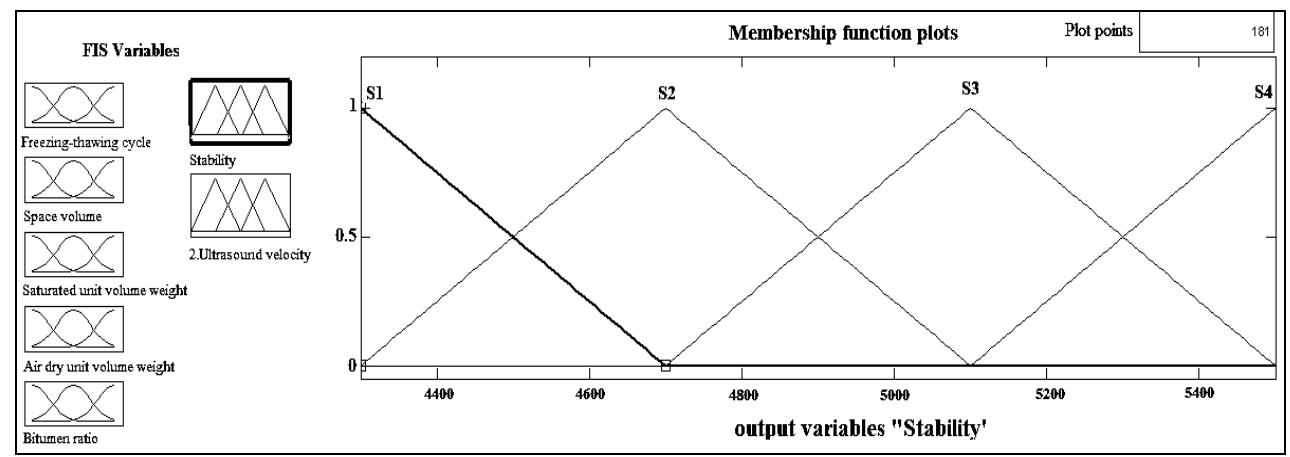

Figure3. Membership functions for Stability.

On the membership function graph, the $y$-axis value has a maximum of $\mu=1$ and minimum of $\mu=0$ for stability and the second ultrasound velocity after freezing/thawing. There are numbers in the range 1-4 on the membership function graphics for each of the 
inputs (number of freezing/thawing cycles, volume of voids, saturated unit volume weight, air dry unit volume weight and bitumen ratio); the outputs of the fuzzy sets are stability and $2^{\text {nd }}$ ultrasound velocity. Each number used in a membership function represents a description. The descriptions and abbreviations of the membership functions are explained. The descriptions are: 1, least; 2, little; 3 , medium; and 4, high. The abbreviated membership functions are: number of freezing-thawing cycles (FT), volume of voids (V), saturated unit volume weight (SW), dry air unit volume weight (AW), bitumen ratio (BR) and ultrasound velocity (UV). An example of a membership function is "FT1", which represents the least of the number freezing/thawing cycles.

\subsection{Rule Editors, Rule Viewer and Surface Viewer}

Fuzzy sets and fuzzy operators are the subjects and verbs of fuzzy logic. These if-then rule statements are used to formulate the conditional statements that comprise fuzzy logic. The if part of the rule is called the antecedent or premise, while the then part of the rule, "Stability and $2^{\text {nd }}$ ultrasound velocity", is called the consequence or conclusion. The rule editor edited the list of the rules that defined the behaviour of the system. The viewer in Fig.4 shows which rules are active and how individual membership function shapes influence the results.

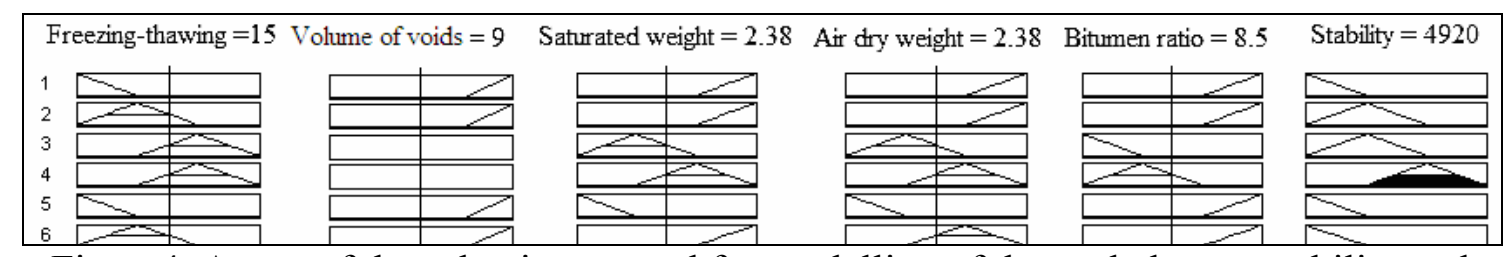

Figure4. A part of the rule viewer used for modelling of the asphalt core stability and $2^{\text {nd }}$ ultrasound velocity.

In addition, the surface map was drawn to display the dependence of the stability and $2^{\text {nd }}$ ultrasound velocity on the number of freezing/thawing cycles, dry air unit volume weight and volume of voids. The surface map shows the behaviour of the entire system in Fig. 5-6.

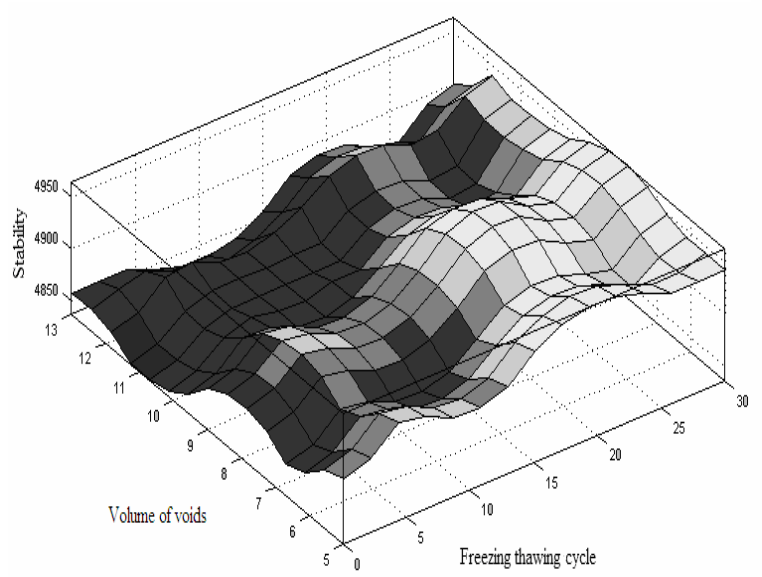

Figure5. The surface map for stability based on the number of freezing thawing cycles and volume of voids

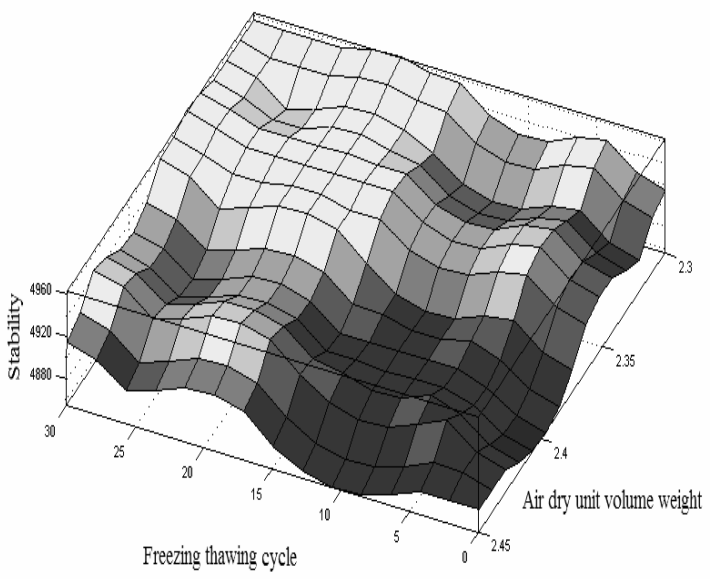

Figure6.The surface map for stability based on freezing thawing recycle and air dry unit volume weight 
The relationship between the values predicted with fuzzy logic and the experimental test results for stability and ultrasound velocity are shown in Fig.7-8.

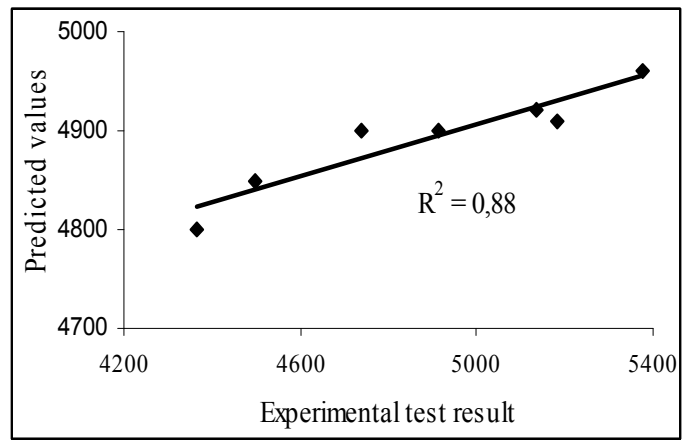

Figure 7. The relationship between the values predicted with fuzzy logic and the experimental stability test results

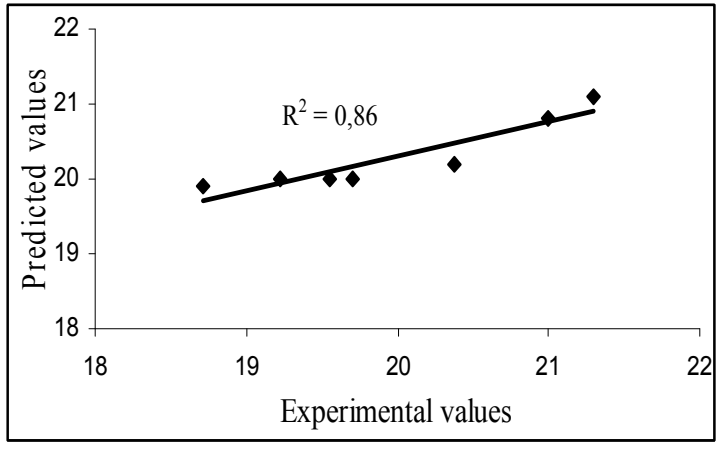

Figure 8 . The relationship between the values predicted with fuzzy logic and the experimental ultrasound velocity test results

\section{RESULTS AND DISCUSSION}

The results showed that the stability of asphalt core samples exposed to freezing and thawing cycles increased, and this increase varied between $22.7 \%$ for a 5 -day cycle and $19.2 \%$ for a 30 -day cycle. The relationships between the experimental results, the fuzzy logic model and the statistical results showed good correlations; the correlation coefficients for the stability of asphalt core samples were $\mathrm{R}^{2}=0.88$ for the fuzzy logic model and $\mathrm{R}^{2}=1.0$ for the statistical method. The correlation between the stability and the number of freezing/thawing cycles was 0.18 . Thus, the freezing/thawing day cycle did not affect stability. This also applied to the correlation between stability and the first ultrasound velocity, which was -0.29 . The results of this study indicated that the ultrasound velocity decreases while the stability increases. After freezing/thawing cycles, the correlation between the stability and the ultrasound velocity was 0.18 , and therefore the freezing/thawing process appears not to affect the ultrasound values. The correlation between volume of voids and stability was -0.93 ; the volume of voids had a marked negative effect on stability. The correlations between stability, saturated unit volume weight and dry air unit volume weight were almost the same at -0.3 . The bitumen ratio had a negative effect on stability, with a correlation between the two of 0.59. The stability decreased as the bitumen ratio increased under varying freezing/thawing conditions. In addition, under different freezing/thawing conditions, the relationship between stability and flow was -0.35 ; that is, as the stability increased, the flow decreased. This result can be explained by the decrease in ductility and increase in viscosity of the bitumen, leading to decreased fluidity and increased stability due to the freezing/thawing cycling. The overall results indicated that an increase in number of freezing/thawing cycles increased the stability of the asphalt core samples by a small amount. The results also showed that the fluidity of the bitumen decreased with exposure to freezing/thawing cycles, which decreased the ductility and increased the viscosity. 


\section{REFERENCES}

1. Robert, R. L., Kandhal, P. S., Brown, E. R., Lee, D., Kennedy, T. W. Hot Mix Asphalt Materials, Mixtures, Design, and Construction, 1st ed. Lanham, Maryland: NAPA Education Foundation; 490p.,1999.

2. Tigdemir, M., Karasahin, M., and Sen, Z., Investigation of fatigue behaviour of asphalt concrete pavements with fuzzy logic approach. International Journal of Fatigue, 24 (8):903910, 2002.

3. Cooper, K. E, and Pell, P. S., The effect of mix variables on the fatigue strength of bituminous materials, TRRL Report 633, 1974.

4. Isacsson, U., and Zeng, H., Cracking of asphalt at low temperature as related to bitumen rheology. Journal of Materials Science, 33(8):2165-2170, 1998.

5. Krishnan, J. M., and Rajagopal, K. R., Triaxial testing and stress relaxation of asphalt concrete. Mechanics of Materials, 36 (9):849-864, 2004.

6. Özgan, E., Determining the stability of asphalt concrete at varying temperature and exposure times using destructive and non-destructive methods, Journal of Applied Sciences, 7 (24): 3870-3879, 2007.

7. Ukwuoma, O., Ademodi, B., The effects of temperature and shear rate on the apparent viscosity of Nigerian oil sand bitumen. Fuel Process Techno, 60:95-101,1999.

8. Gardiner, M. S, Brown, E. R., Segregation in hot-mix asphalt pavements, NCHRP Report 441, Washington, DC, USA, National Academy Press., 2000.

9. Bahia, H. U, Hanson, D.I., Characterization of modified asphalt binders in super pave mix design, NCHRP Report.441, National Academy Press, Washington, DC, USA., 2001.

10. Petersen, J. C., Robertson., R. E., Branthaver, J. F., Harnsberger, P. M., Duvall, J. J., Kim, S. S., Anderson, D. A., Christiansen, D. W.; Bahia, H. U., Binder characterization and evaluation, SHRP Report A-367;1. 1994.

11. Coplantz, J. S, Yapp, M. T., Finn, F.N., Review of relationships between modified asphalt properties and pavement performance, SHRP-A-631, 1993.

12. Sousa, J. B., Development and use of the repeated shear test (constant height): an optional Superpave mix design tool. Strategic Highway Research Program Report, SHRP-A-698, 1994.

13. Kandhal, P. S., Rao, S. S., WTSON, d. E., Young, B., Performance of recycled hot mix asphalt mixtures, , NCA Technology Report, 95-01, 1995.

14. Huner, M. H., Brown, E. R., Effects of re-heating and compaction temperature on hot mix asphalt volumetric, NCA Technology Report, 2001

15. West, R. C., Development of rapid QC procedures for evaluation of HMA properties during production., NCAT Report, 2005.

16. McDaniel, R. S., Anderson, R. M., Recommended use of reclaimed asphalt pavement in the super pave mix design. NCH Research Program Web Document, 30:D9-12, Contractor's Final Report, 2000.

17. Gudimettla, J. M., L. Allen, C. Jr., and Brown E. R., Workability of Hot Mix Asphalt. NCAT Report 03-03, Auburn University, Auburn Alabama, 2003.

18. Özgan, E., Kap, T., The effects of exposure time and environment temperature to the ductility on asphalt cements, Journal of the Institute of Science and Technology of Sakarya University, 9 (1):43-47, 2005.

19. Krishnan, J. M., Rao, C. L., Permeability and bleeding of asphalt concrete using mixture theory, International Journal of Engineering Science, 39:611-627, 2001. 
20.Epps, J. A., Sebaaly, P. E., Peneranda, J., Maher, M. R., McCann, M. B., Hand, A. J., Compatibility of a test for moisture-induced damage with Super pave volumetric mix design, NCHRP Report 444, Washington, DC, USA, National Academy Press. 2000.

21.Epps, J. A., Hand, A., and Sebaaly, P., Recommended performance-related specification for hot-mix asphalt construction: results of the Wes Track project, NCHRP Report 455, Washington, DC, USA, National Academy Press. 2002.

22.Rauhut, J. B., Simpson, A. L., Daleiden, J. F., Darter, M. I., Owusu-Antwi, E., Pendleton, O. J., Early analyses of long-term pavement performance general pavement studies data: lessons learned and recommendations for future analyses, Transportation Research Board Business Office, SHRP-P-680, 1994.

23.ASTM D2172 Standard Test Methods for Quantitative Extraction of Bitumen from Bituminous Paving Mixtures.

24.Mamdani, E. H., Assilian, S., An Experiment in Linguistic Synthesis with a Fuzzy Logic Controller, International Journal of Human-Computer Studies, 51 (2): 135-147, 1999.

25.Sugeno, M., Introductory survey of fuzzy control, INFO.Sci.,(36):1-2,59-83, 1985. 26.Zadeh, L., Man and Computer, Outline of a new approach to the analysis of complex systems and decision processes., IEEE Bordeaux, France, 130-165, 1972. 